\title{
AFIP-4 Fabrication Summary Report
}

\author{
Glenn A. Moore
}

February 2010

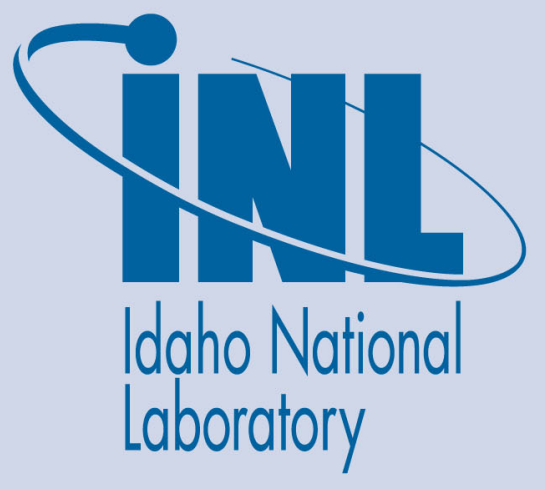

The INL is a U.S. Department of Energy National Laboratory operated by Battelle Energy Alliance 
INL/EXT-09-17423

\title{
AFIP-4 Fabrication Summary Report
}

\author{
Glenn A. Moore
}

February 2010

\section{Idaho National Laboratory \\ Idaho Falls, Idaho 83415}

http://www.inl.gov

\author{
Prepared for the
}

U.S. Department of Energy

Office of National Nuclear Security Administration

Under DOE Idaho Operations Office

Contract DE-AC07-05ID14517 


\section{DISCLAIMER}

This information was prepared as an account of work sponsored by an agency of the U.S. Government. Neither the U.S. Government nor any agency thereof, nor any of their employees, makes any warranty, expressed or implied, or assumes any legal liability or responsibility for the accuracy, completeness, or usefulness, of any information, apparatus, product, or process disclosed, or represents that its use would not infringe privately owned rights. References herein to any specific commercial product, process, or service by trade name, trade mark, manufacturer, or otherwise, does not necessarily constitute or imply its endorsement, recommendation, or favoring by the U.S. Government or any agency thereof. The views and opinions of authors expressed herein do not necessarily state or reflect those of the U.S. Government or any agency thereof. 



\section{AFIP-4 Fabrication Summary Report}

INL/EXT-09-17423

February 2010

Approved by:

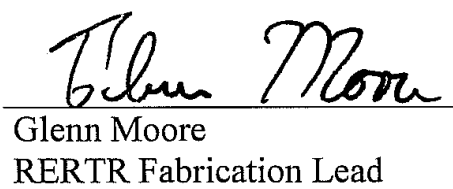

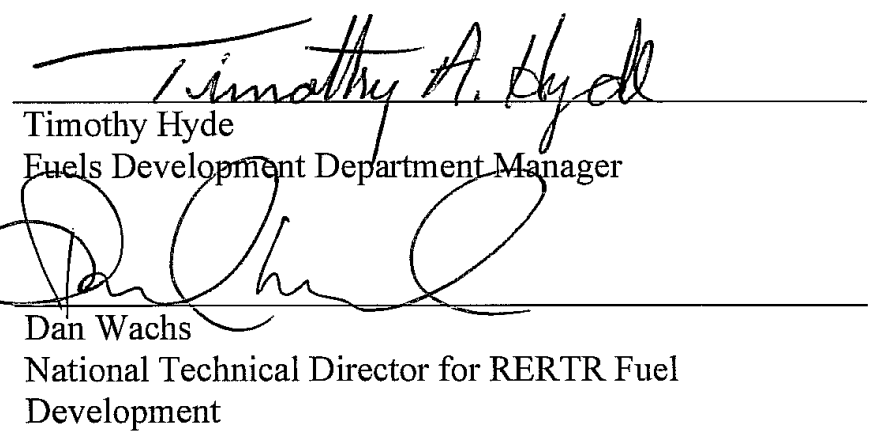

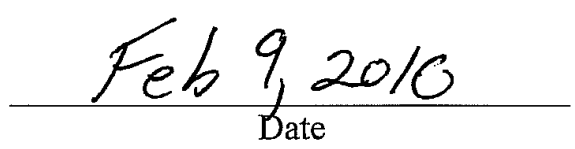

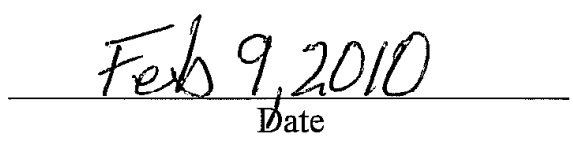

$\frac{\text { Feb } 9,2010}{\text { Date }}$ 



\begin{abstract}
The Advanced Test Reactor (ATR) Full-size Plate In Center Flux Trap Position (AFIP)-4 experiment was designed to evaluate the performance of monolithic fuels at a scale prototypic of research reactor fuel plates. Twelve qualified fueled plates were fabricated for the AFIP-4 experiment to be irradiated in the INL ATR. This report provides details of the fuel fabrication efforts, including material selection, fabrication processes, and fuel plate qualification.
\end{abstract}




\section{ACKNOWLEDGEMENTS}

The following people were instrumental in a successful AFIP-4 fabrication effort: Francine Rice, Doug Burkes, Jan Fong Jue, Jared Wight, Mike Chapple, Pat Hallinan, Blair Park, Steve Steffler, Curtis Clark, David Cottle, Steven Taylor, Susan Case, Paul Wolf, Nicolas Woolstenhulme, and the MFC Quality Assurance Department. Work supported by the U.S. Department of Energy (DOE), Office of Nuclear Nonproliferation and Security Affairs (NNSA) under DOE Office of Nuclear Energy, Science, and Technology Idaho Operations Office Contract DE AC07 05ID14517. 


\section{CONTENTS}

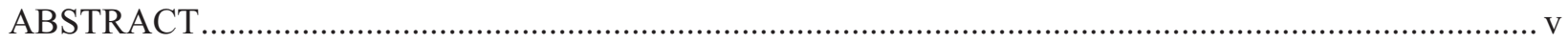

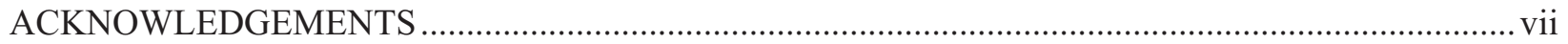

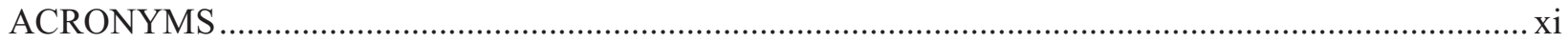

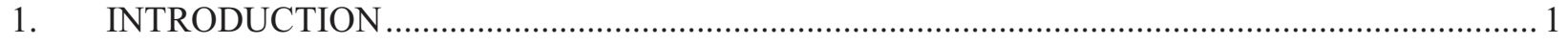

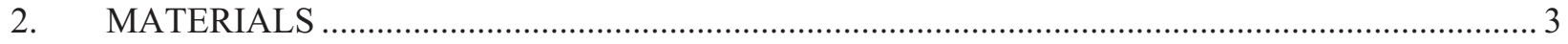

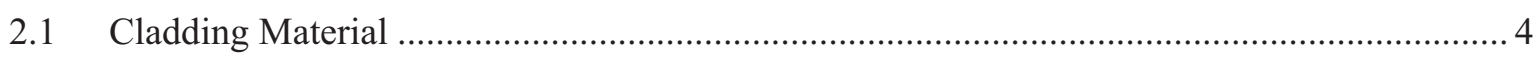

2.2 Zirconium Diffusion Barrier Material............................................................................... 4

3. FOIL FABRICATION OF CO-ROLLED ZR FOILS ............................................................. 4

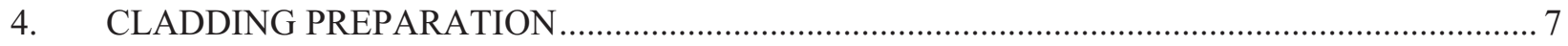

5. FRICTION BONDING FUEL PLATE FABRICATION …................................................... 8

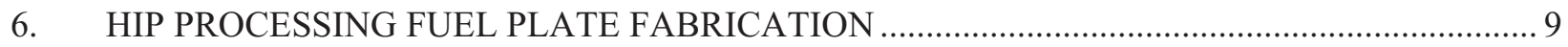

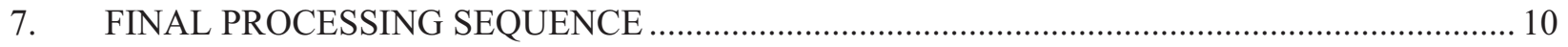

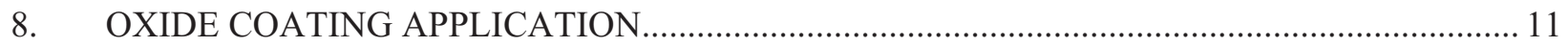

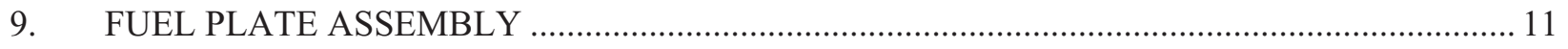

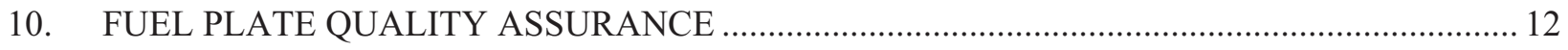

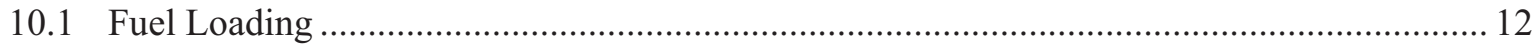

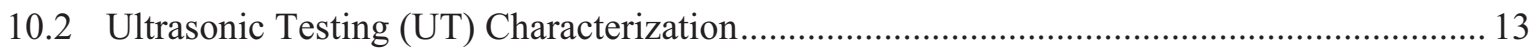

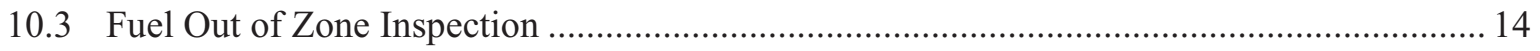

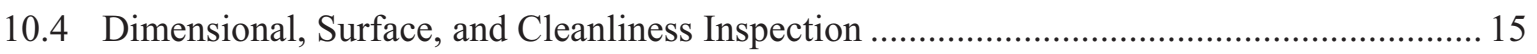

10.5 Bend Testing and Bend Test Sample Inspection.............................................................. 15

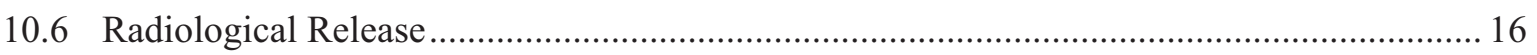

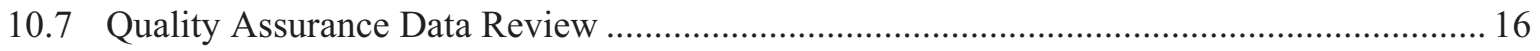

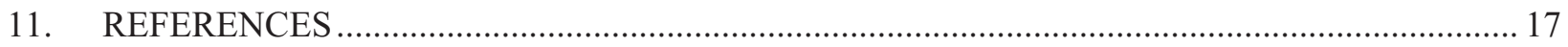

\section{FIGURES}

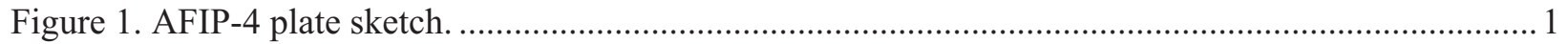

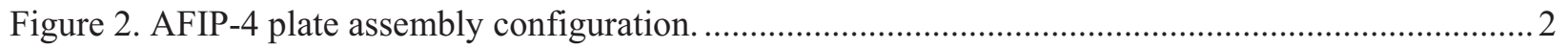

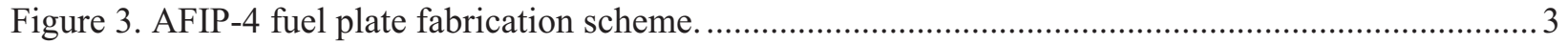

Figure 4. Image showing AFIP-4 hot rolling assembly components prior to final lay-up and welding. ..... 
Figure 5. Graph of rolling assembly thickness and maximum pass force during $\mathrm{Zr} / \mathrm{U} 10 \mathrm{Mo}$ corolling foil fabrication process.

Figure 6. Hot rolling assembly post rolling and annealing, prior to foil removal.................................... 6

Figure 7. Sheared and polished AFIP-4 Zr co-rolled U10Mo fuel foil prior to clad bonding. .................... 7

Figure 8. TTI friction bonding system used for AFIP-4 fuel plate fabrication. .......................................... 8

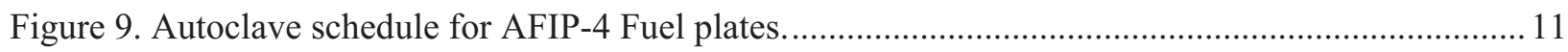

Figure 10. AFIP-4 fuel plate frame assembly construction: FB plates residing in A frame assembly and HIP plates in the B frame assembly.............................................................. 12

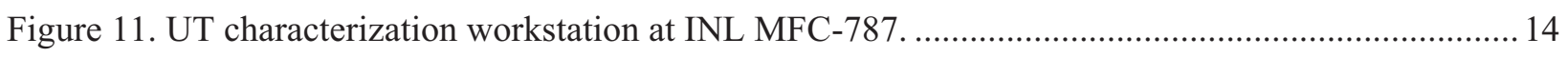

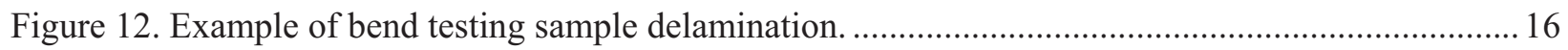

\section{TABLES}

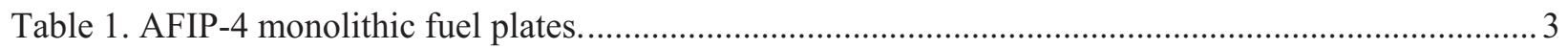

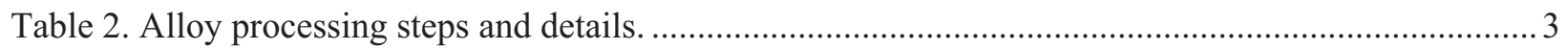

Table 3. Summary of Y-12 data for as-received U10Mo alloys incorporated into AFIP-4 fuel

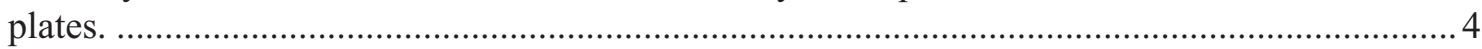

Table 4. Aluminum chemical cleaning processing steps and conditions................................................ 8

Table 5. Friction bonding parameters used for the AFIP-4 fuel plate.................................................... 9

Table 6. Summary of fuel loading acceptance criteria and AFIP-4 plate data......................................... 13

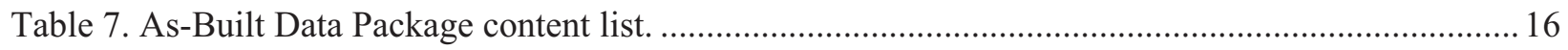




\section{ACRONYMS}

AFIP Advanced Test Reactor (ATR) Full-size Plate In Center Flux Trap Position

ATR Advanced Test Reactor

CFT Center Flux Trap

DI deionized

FB friction bonding

FGMS Fission Gas Monitoring System

FOZ Fuel out of Zone

HFEF Hot Fuel Examination Facility

HIP Hot Isostatic Pressed

ID identification

INL Idaho National Laboratory

MFC Material and Fuels Complex

NCR Non-Conformance Report

NNSA Office of Nuclear Nonproliferation and Security Affairs

QA Quality Assurance

RERTR Reduced Enrichment for Research and Test Reactors

TTI Transformation Technologies Inc.

UT ultrasonic testing 


\section{AFIP-4 Fabrication Summary Report}

\section{INTRODUCTION}

The Advanced Test Reactor (ATR) Full-size Plate In Center Flux Trap Position (AFIP)-4 experiment was designed to evaluate the performance of monolithic fuels at a scale prototypic of research reactor fuel plates. A detailed description of the experiment can be found in PLN-3028, Experiment Control Plan for the AFIP-4 Fuel Irradiation in the ATR. Requirement for the fuel plates qualified for the experiment can be found in TFR-573, Rev. 1. Fuel Plate Specification For RERTR And AFIP Series Fuel Irradiations In The ATR. Twelve qualified fueled plates were fabricated for the AFIP-4 experiment and subsequently inserted into the Idaho National Laboratory (INL) ATR for irradiation. Irradiated samples will be used in fission product retention studies using a Fission Gas Monitoring System (FGMS) to be established within the Hot Fuel Examination Facility (HFEF) at the INL's Material and Fuels Complex (MFC).

Fuel plate assemblies were prepared for irradiation in the Center Flux Trap (CFT) of the ATR using the existing AFIP hardware. Each frame assembly holding six identical fuel plate samples. Fuel plate frame assemblies were designated A and B. A sketch of each the fuel plate's critical dimensions is shown in Figure 1. Friction-bonded (FB) plates will be placed in AFIP-4 fuel plate assembly Frame A, and Hot Isostatic Pressed (HIP) fuel plates established in fuel plate Assembly B. Figure 2 shows the AFIP-4 plate assembly configuration.

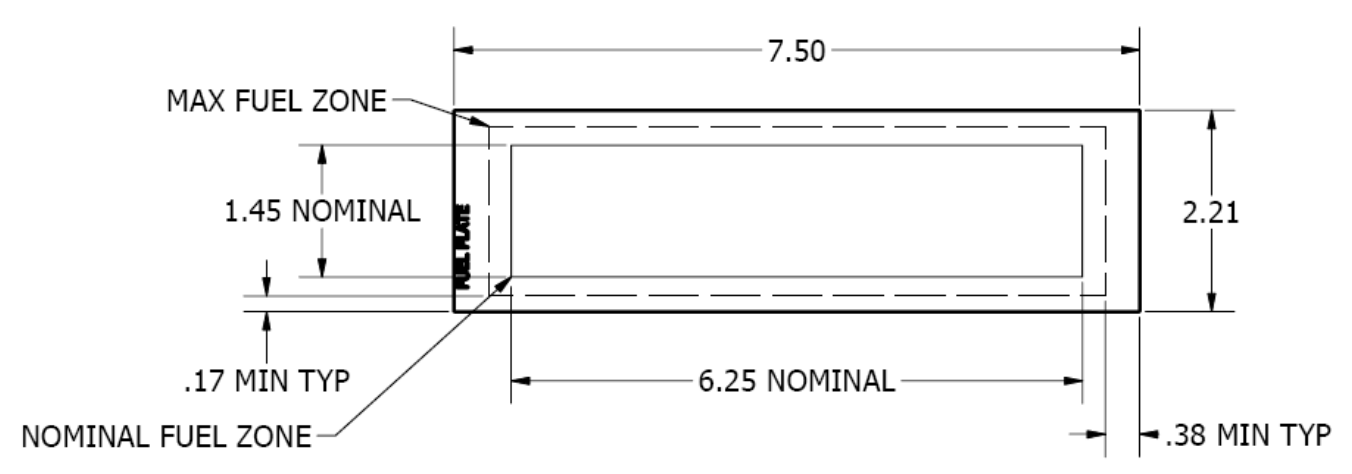

Figure 1. AFIP-4 plate sketch.

The fuel phase in all fuel plates will be U10Mo at $~ 19.75 \%$ U-235 enrichment. A zirconium diffusion barrier was applied to each fuel coupons supplied by the Y-12 National Security Complex. Thus realizing a monolithic fuel foil having a nominal fuel thickness being 0.013 in. with an additional $0.001 \mathrm{in}$. of $\mathrm{Zr}$ applied to both sides of the fuel yielding a total nominal foil thickness of $0.015 \mathrm{in}$. The cladding material used was 6061-T6 aluminum.

The plates were fabricated as described in PLN-3037, "Fabrication Control Plan for the AFIP-4 Experiment." The plates were fabricated at MFC by the Reduced Enrichment for Research and Test Reactors (RERTR) Fabrication Group from February to April 2009.

The AFIP-4 experiment consisted of two aluminum-clad monolithic fuel plates utilizing a metallic foil of U10Mo with $19.75 \%$ U-235 enrichment. The cladding material used was 6061-T6 aluminum. The fuel plate dimensions per INL Drawing 759269, “AFIP-4 Fuel Plate,” are summarized in Table 1. 
This report provides details of the fuel fabrication efforts, including material selection, fabrication processes, and fuel plate qualification. The nominal fuel plate attributes are summarized in Table 1. A plate-fabrication process flow diagram is represented in Figure 3.

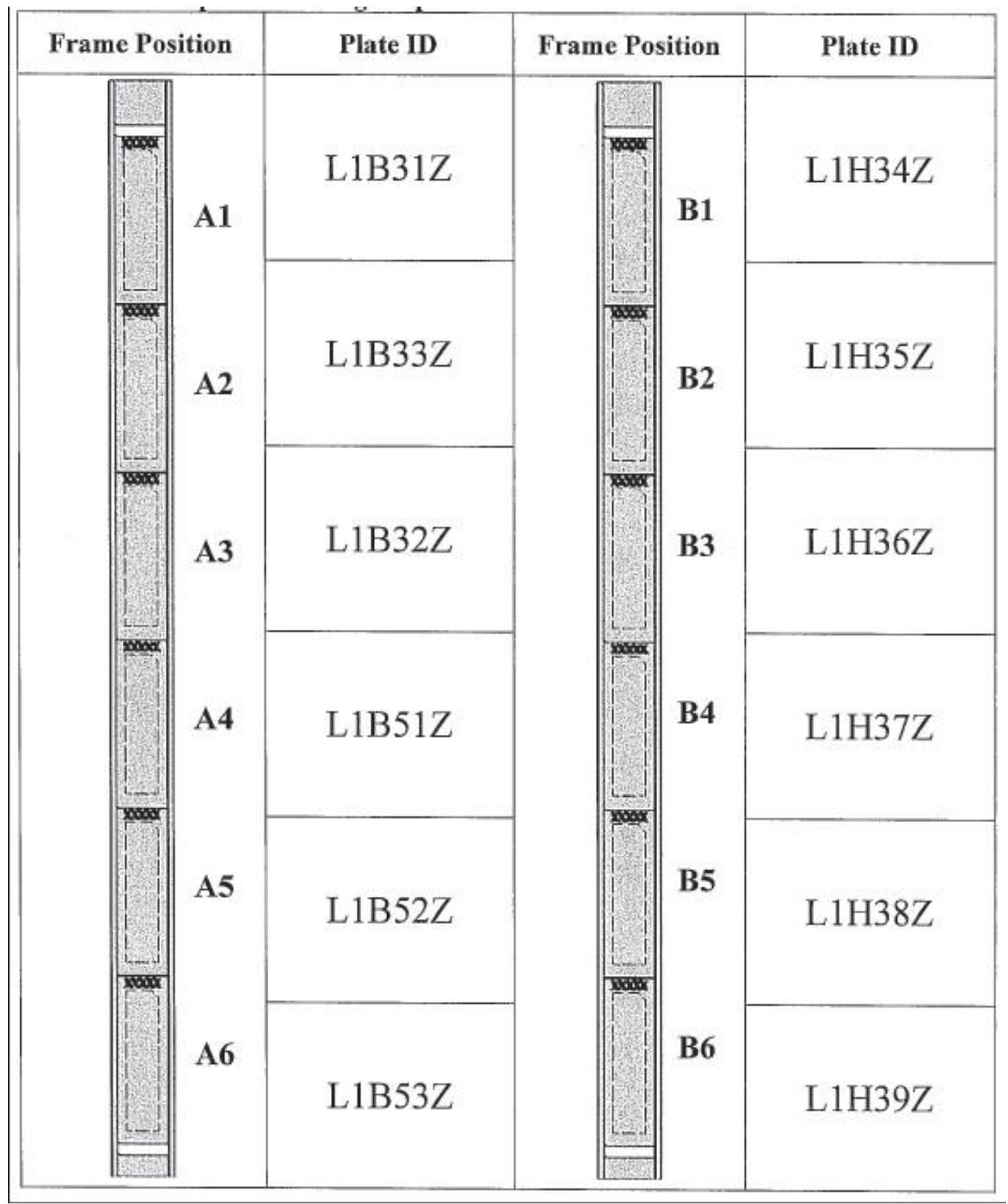

Figure 2. AFIP-4 plate assembly configuration. 
Table 1. AFIP-4 monolithic fuel plates.

\begin{tabular}{|l|ll|}
\hline $\begin{array}{c}\text { Plate } \\
\text { Type }\end{array}$ & \multicolumn{1}{c|}{ Attributes } \\
\hline & $\bullet \quad$ Uranium Molybdenum Fuel Alloy: U10Mo nominal \\
& - Uranium Enrichment: $19.9 \mathrm{wt} \%$ U enrichment nominal \\
HIP/FB & $\begin{array}{l}\text { - Fuel Meat Thickness: } 0.013 \text { in. nominal } \\
\end{array}$ & $\begin{array}{l}\text { Cladding: } 6061 \text { aluminum } \\
\text { - Reaction Barrier } \sim 0.001 \text { in. thick Zirconium (Zr) layer applied to foil via hot rolling } \\
\end{array}$ \\
\hline
\end{tabular}

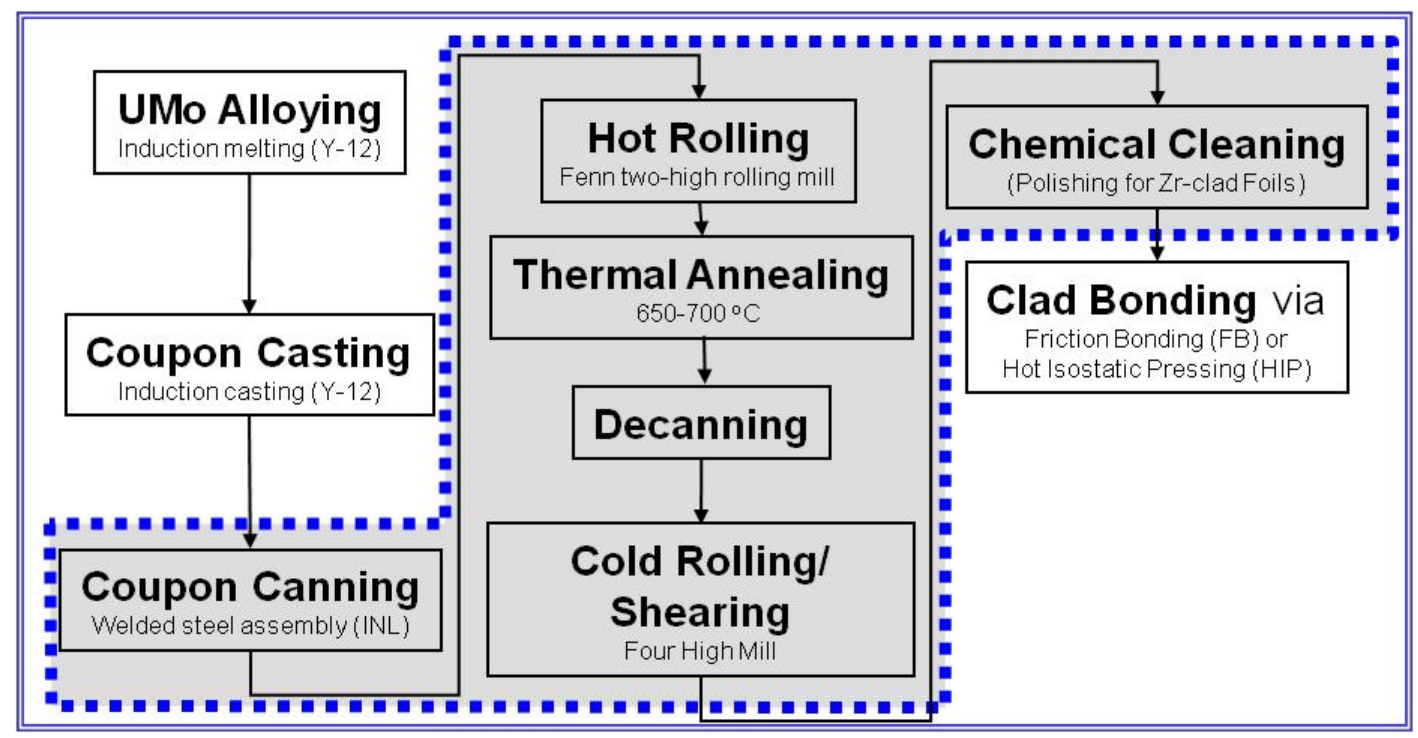

Figure 3. AFIP-4 fuel plate fabrication scheme.

\section{MATERIALS}

The U10Mo fuel alloy material was supplied by the Y-12 National Security Complex in the form of machined LEU10Mo coupons. The preparation of the LEU10Mo alloy coupons Y-12 as established is in Table 2 .

Table 2. Alloy processing steps and details.

\begin{tabular}{|l|l|}
\hline \multicolumn{1}{|c|}{ Alloy Processing Step } & \multicolumn{1}{c|}{ Details } \\
\hline \multirow{3}{*}{ Pre-Melt Casting } & $\begin{array}{l}\text { Induction melting and casting of HEU, Low-Assay Diluent (DU), Alloy } \\
\text { Material (Mo) in proportion to yield U10Mo with nominally 19.9\% U-235 } \\
\text { enrichment. }\end{array}$ \\
\hline \multirow{3}{*}{ Final Casting } & $\begin{array}{l}\text { Induction melting and casting of U10Mo alloy } \\
\text { Charge size: } \sim 5 \mathrm{~kg}, \text { casting dimensions: } 9.75 \text { in. length } \times 8 \text { in. width } \times \\
0.190 \text { in. thickness }\end{array}$ \\
\hline Coupon Machining & $\begin{array}{l}\text { Machined coupons } \sim 4.0 \text { in. length } \times \sim 3.0 \text { in. width } \times \sim 0.09 \text { in. thickness, } \\
\sim 300 \mathrm{~g}\end{array}$ \\
\hline
\end{tabular}


Summary data of the as-received U10Mo coupon material used to produce the AFIP-4 fuel plates is summarized in Table 3. The Y-12 provided chemical analysis/certification documentation can be found in INL Rec./Doc. ID 2600687, "RERTR AFIP-4 Irradiation Experiment in the ATR, As-Built Data Package, INL."

Table 3. Summary of Y-12 data for as-received U10Mo alloys incorporated into AFIP-4 fuel plates.

\begin{tabular}{|c|c|}
\hline Item/Data & Value \\
\hline \multicolumn{2}{|l|}{ Coupons 193, 194} \\
\hline Mo (wt\%) & $9.88 \%$ \\
\hline Uranium Enrichment (wt\% U235) & $19.92 \%$ \\
\hline Carbon content (ppm) & 472 \\
\hline \multicolumn{2}{|l|}{ Coupons 195, 196} \\
\hline Mo (wt $\%)$ & $9.73 \%$ \\
\hline Uranium Enrichment (wt\% U235) & $19.91 \%$ \\
\hline Carbon content (ppm) & 472 \\
\hline \multicolumn{2}{|l|}{ Nominal Coupon Size } \\
\hline Weight (g) & 300 \\
\hline Length (in.) & 4.0 \\
\hline Width (in.) & 3.0 \\
\hline Nominal Thickness (in.) & 0.09 \\
\hline
\end{tabular}

\subsection{Cladding Material}

The cladding material used for the AFIP-4 fuel plates was 6061-T6 aluminum. Three thicknesses of aluminum sheet were utilized: 0.040 in. for the "bottom" foil-pocket cladding (HIP), 0.032 in. for the "bottom" foil-pocket cladding (FB), and 0.025 in. for the "top cover" cladding (FB and HIP cladding processes).

\subsection{Zirconium Diffusion Barrier Material}

Alfa Aesar Zirconium Foil, 0.25mm (0.010 in.), 99.8\% metal basis

\section{FOIL FABRICATION OF CO-ROLLED ZR FOILS}

A Zr co-rolled fuel foil was used in the fuel plate " $2 \mathrm{BZ}$.". The foil was processed from a cast and machined U10Mo coupon, nominally 4 in. long $\times 3.0$ in.wide $\times 0.090$ in. thick. The long dimension of the coupon was of vertical orientation with respect to the as-cast ingot.

Prior to foil fabrication activities, the coupon edges and corners were rounded using a file to prevent breaching of the rolling can during processing. The alloy coupon was acid cleaned to remove any surface oxide contamination. A 30\% nitric acid solution was used, followed by a deionized (DI) water rinse, and ethanol wipe down.

The cleaned coupon was then placed into a previously prepared hot-rolling assembly made of low carbon steel within minutes of completing the cleaning step. The assembly consisted of a top and bottom plate, and a picture frame mid-plate, each $\sim 0.090$ in. thick (Figure 4). Internal surfaces and edges of the rolling assembly plates were brushed with a stainless steel brush mounted in a drill press. The inside faces 
of the top and bottom plates were coated with Neolube ${ }^{a}$ to prevent the zirconium foil, adjacent to the alloy coupon, from adhering to the assembly during hot rolling. Neolube coated plates were heated at $100^{\circ} \mathrm{C}$ for 10 minutes to remove residual solvent.

In the preparation of the rolling assembly, two pieces of 0.010 in. thick zirconium foil were sheared slightly larger than the coupon dimensions to completely overlay the coupon's faces within the rolling assembly. The zirconium foils were cleaned with acetone prior to use and spot welded at uncoated locations on the Neolube-coated cover plates.

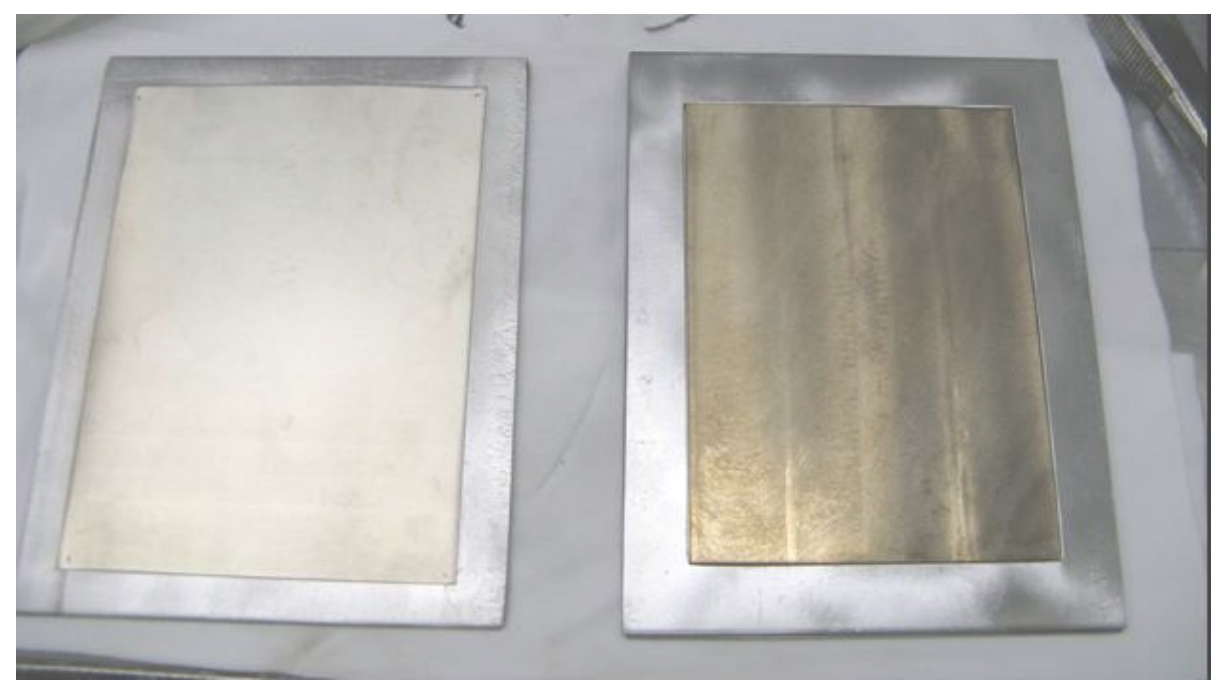

Figure 4. Image showing AFIP-4 hot rolling assembly components prior to final lay-up and welding.

After lay-up, the rolling assembly was temporarily clamped together, moved to an argon atmosphere glove box, and edge welded on all four sides.

The welded rolling assembly was preheated in a box furnace for 30 minutes at $650^{\circ} \mathrm{C}$, after which the assembly was removed from the furnace using tongs and passed through a two-high rolling mill. After three reduction passes and a zero pass, the assembly was returned to the furnace, reheated (10-15 minutes), and the rolling process repeated. After four to six four-pass reduction sets, the number of passes per set was reduced to two reduction passes and an optional zero pass (at the operators' discretion), which is based on observation and sound of the rolling assembly during processing. Namely, passing the rolling assembly after too much cooling can resulting in rippling of the assembly, which is mitigated via reheating and reduction of roller speed.

An example of rolling assembly thickness reduction over time and maximum per pass force in shown in Figure 5. Four passes per sequence are represented for each of the first four data points. The remaining 11 data points reflect single passes made between each furnace reheat. A total of 30 rolling passes were performed. Typical reheat time is 5 minutes during the later stages of the rolling activity. It should be noted that the largest single pass reduction used was $12 \%$, with a range of 5 to $12 \%$ being employed.

a. PRODUCT DISCLAIMER - References herein to any specific commercial product, process, or service by trade name, trademark, manufacturer, or otherwise, do not necessarily constitute or imply its endorsement, recommendation, or favoring by the U.S. Government, any agency thereof, or any company affiliated with Idaho National Laboratory. 


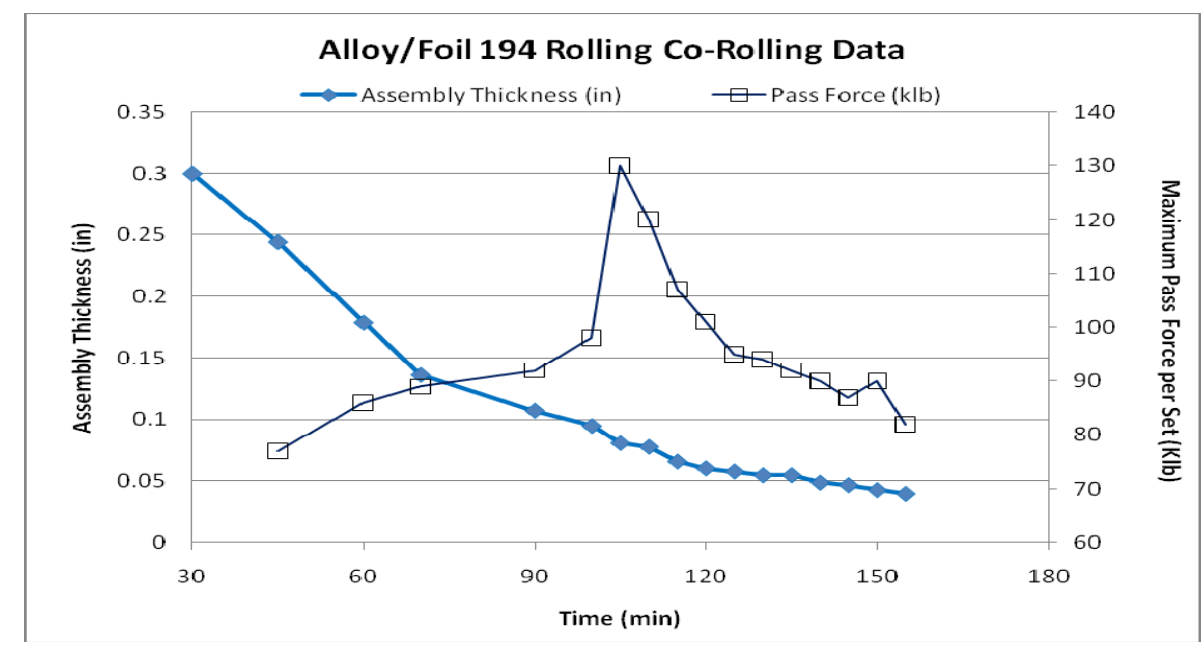

Figure 5. Graph of rolling assembly thickness and maximum pass force during Zr/U10Mo co-rolling foil fabrication process.

After the rolling assembly was reduced to a thickness of $\sim 0.040$ in., the Zr co-rolled foil "still in the can" was annealed for 45 minutes at $650^{\circ} \mathrm{C}$. Figure 6 shows an image of the annealed rolling assembly. Subsequently, the edges of the assembly were sheared away and the foil removed.

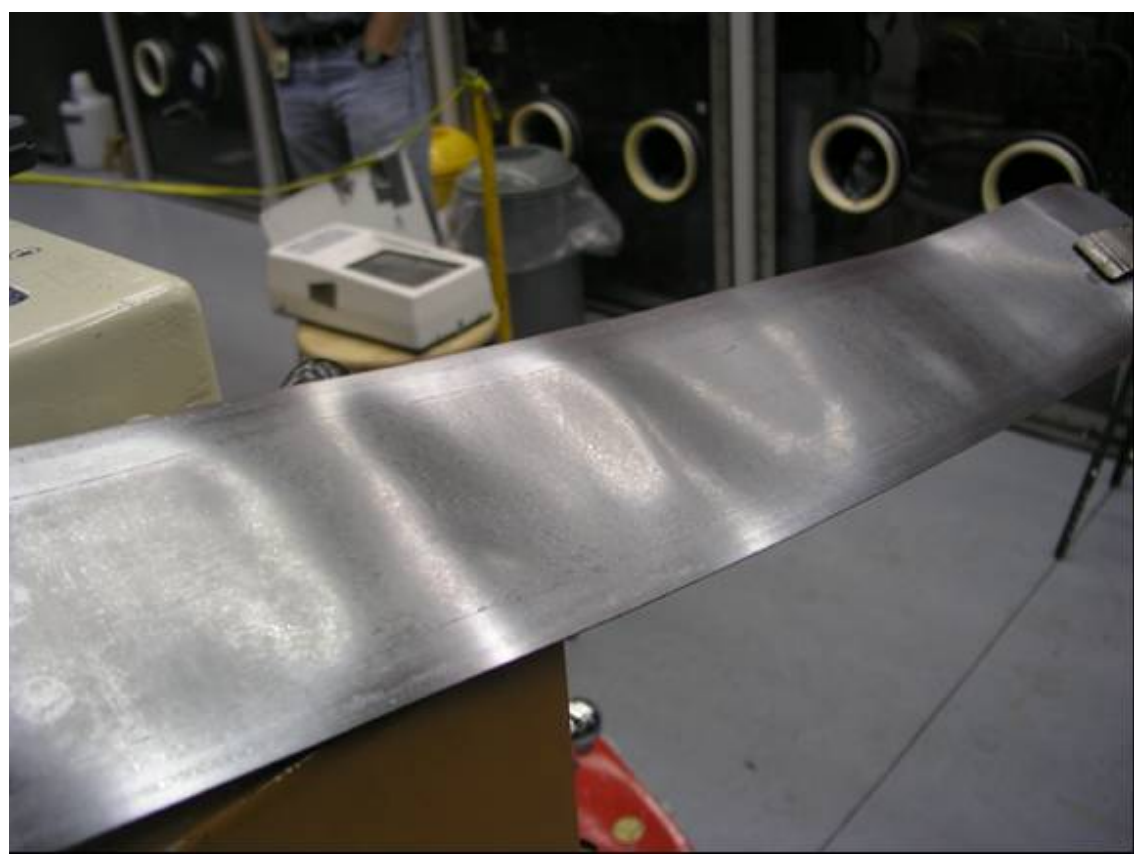

Figure 6. Hot rolling assembly post rolling and annealing, prior to foil removal.

The obtained Zr-clad co-rolled fuel foils were cleaned with ethanol to remove any transferred carbon residue from the Neolube-coated can faces. The foil weight was established, so as to calculated the $\mathrm{wt} \%$ $\mathrm{Zr}$ established. Foil dimension were also obtained. The hot rolled foil thickness was targeted to be $\sim 120$ $125 \%$ of the final foil thickness, thus, allowing cold rolling to be used to "smooth out" any fuel meat thickness variability". Co-rolled foils obtained had the following nominal dimensions: 3.3 in. wide $\times 21$ in. long $\times 0.018-0.020$ in. thick. 
Note that during the processing of one of the AFIP-4 Foil 193, the rolling assembly was breached, resulting in an obtained thickness less than the target values. The breached can was "mended" via welding in the argon glove box, reheated, and rolled an additional pass, after which it was established that minor radiological contamination was presented in the "mended" region of the can assembly. The foil was subsequently decanned leaving a foil having a thickness of 0.023-0.025 in. A $4.75 \mathrm{in}$. long segment of the Foil 193 was sheared for cold rolling. Edge cracking of the foil was observed after the foil had been reduced to a thickness of 0.0215 in. (from 0.023 in.) after four "effective" passes. Thus, it was concluded that "foil annealing" after co-rolling is required. Subsequently, Foil 193 segments were encapsulated inside stainless steel envelopes and annealed at $650^{\circ} \mathrm{C}$ for 1 hour. The annealed foils were reduced to the $\sim 0.0148$ in. target thickness via the cold rolling process, as described below.

Cold rolling of AFIP-4 foils was performed on $\sim 5$ in. long segments of the obtained co-rolled foil, which had been annealed at the conclusion of the co-rolling activity, or subsequently. Each $\sim 3.3 \mathrm{in}$. wide $\times 5$ in. long foil was reduced to a nominal target thickness of 0.0148 in., using nominally 12 cold rolling passes, six-pass sets, in which the foil experienced a reduction pass and then was face-flipped and given a zero pass. Reduction of 0.0004-0.001 in. per two-pass set was accomplished.

After cold rolling, each foil segment was sheared into two AFIP-4 size foils. Hence, it produced eight 1.5 in. wide $\times 6.25$ in. long fuel foils per coupon, except for coupon/foil 193 that needed to be shortened to remove oxidation associated with the can breaching/mending activity described above.

Sheared fuel foils were prepared for the cladding application process (either FB or HIP) by first polishing the Zr-clad surface using a water-based diamond polishing compound to remove any oxidation and surface contamination; compound residue was removed using DI water, ethanol, and lint-free cloths. Figure 7 shows a picture of an AFIP Zr co-rolled U10Mo foil ready for clad bonding.

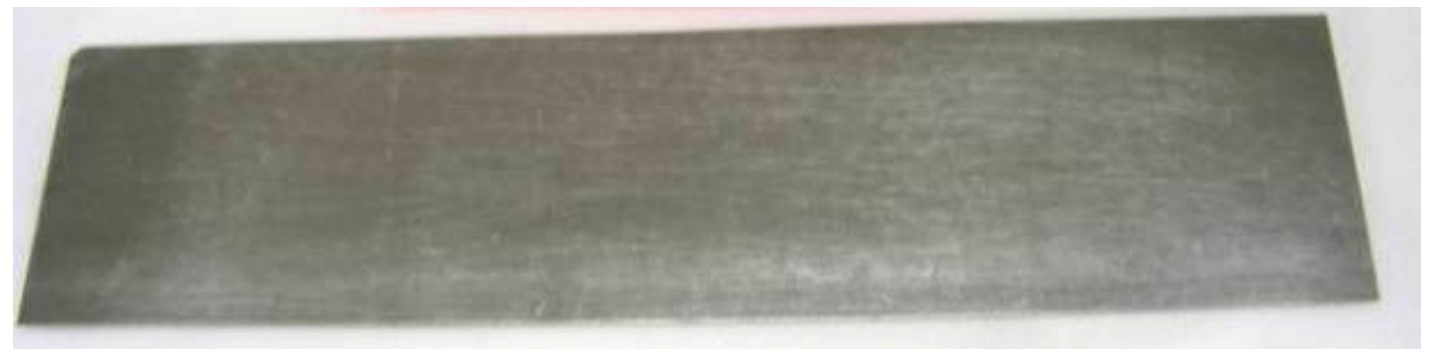

Figure 7. Sheared and polished AFIP-4 Zr co-rolled U10Mo fuel foil prior to clad bonding.

\section{CLADDING PREPARATION}

6061 aluminum cladding preparation for an FB plate and hot isostatically bonded plates is established to be slightly different given the distinct features of each process. Namely, the FB process is quite dynamic with respect to interaction with the cladding material, imparting low temperature forming forces that recreate the microstructure of the starting cladding material, and establishing a fine grain clad that is of little resemblance to the starting material. The HIP process, in contrast, "presses" versus "stirs" the Al$\mathrm{Al}$ interface together; as such, the HIP process relies/depends upon a starting point of "as-clean-aspossible" Al-Al interfaces - one free of oxide contamination. As such, it is currently the approach of the RERTR fabrication group to mechanically brush bonding surfaces of cladding materials with a stainless steel brush in preparation for each clad bonding process, and to additionally, caustically clean aluminum sheet surfaces used in the HIP process. Regardless of the preparation route, in both circumstances, the time between cleaning and utilization of the prepared cladding "hardware" is minimized, preferably to a few hours. However, adequate bonding has been accomplished with cleaned cladding material stored in vacuum-sealed sleeves for several days/weeks. 
Aluminum cladding "sets" used for FB and HIP plates were prepared as follows:

1. As-received sheets of 6061-T6 aluminum were sheared to the desired size.

2. Both sides of each cladding piece were then brushed using a 3 in. diameter SS brush held in a milling machine tool holder. The brushing was performed at 600 rotations per minute (rpm) and using a feed rate of 60 in. per minute (ipm).

3. A foil retention pocket was milled into the "pocket plate" sheet material to a depth of 0.007 in. for FB samples and 0.015 in. for HIP samples.

4. For cladding used in the HIP process, the material received an additional chemical cleaning treatment detailed in Table 4.

Table 4. Aluminum chemical cleaning processing steps and conditions.

\begin{tabular}{|l|c|l|c|}
\hline \multicolumn{1}{|c|}{ Chemical Cleaning Step } & Method & Temp $\left({ }^{\circ} \mathrm{C}\right)$ & Time (sec) \\
\hline Degrease (Acetone/ethanol) & Hand & RT & - \\
\hline Basic Etch (2M NaOH solution) & Bath & $80-85$ & $20-120$ \\
\hline Water Rinse/Desmut & Bath & RT & $15-30$ \\
\hline Desmut (sponge, cloth, or brush) & Hand & - & - \\
\hline Pickle (30\% nitric acid solution) & Bath & RT & 120 \\
\hline Water Rinse & Bath & RT & $15-30$ \\
\hline Hot Rinse & Bath & $80-85$ & - \\
\hline Wipe (Lint Free) & Hand & - & - \\
\hline Vacuum Seal (if stored) & Hand & - & \\
\hline Room Temperature (RT) & \multicolumn{2}{|}{} \\
\hline
\end{tabular}

\section{FRICTION BONDING FUEL PLATE FABRICATION}

Friction Bonding (FB) fuel plate fabrication was performed on the INL's Transformation Technologies Inc. (TTI) friction bonding machine configured with a water cooled rotating tool (Figure 8).

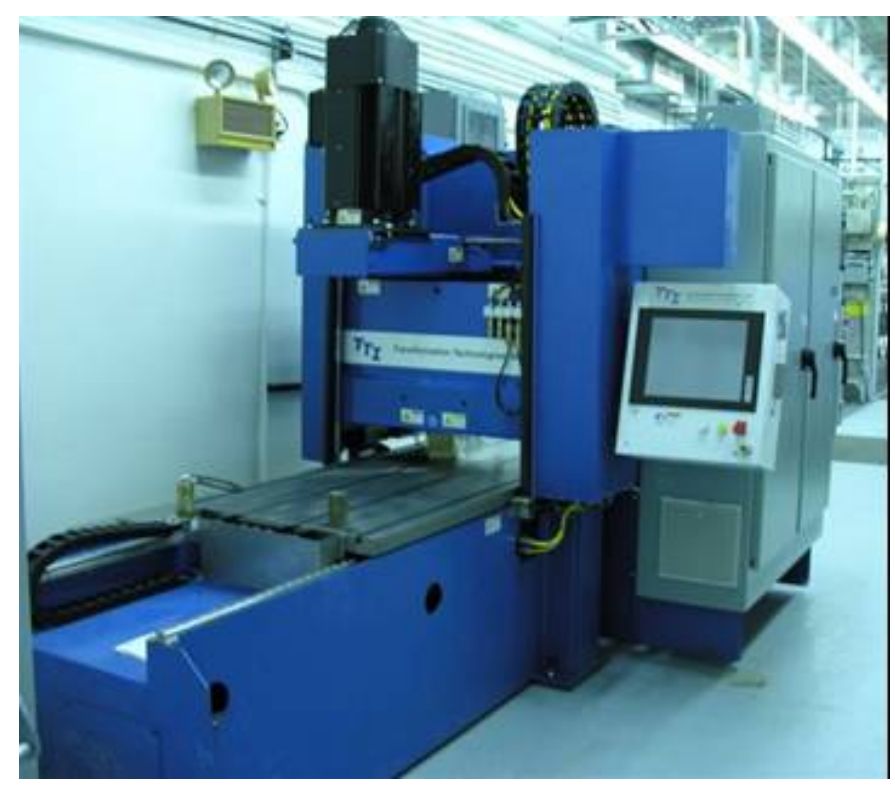

Figure 8. TTI friction bonding system used for AFIP-4 fuel plate fabrication. 
The process consists up preparing a cladding/foil "pack" using a prepared fuel that was prepared for the FB process by placing a fuel foil into the machined "foil retention pocket" of the 0.032 in. thick aluminum cladding. The 0.025 in. cladding sheet "cover" was then layed in place. The cladding/foil layup "pack" was then clamped firmly in place along each longer edge on a processing anvil, located on the translating bed.

Clad/Clad and Clad/Fuel bonding was accomplished using the following steps:

1. Slowly bringing the rotating tool into contact with the cladding material

2. Applying a controlled amount of down force and time to generate thermo-mechanical softening of the cladding material under the tool.

3. Traversing the work piece "clad/foil pack" per parameters listed in Table 5.

4. Stopping the traverse and drawing out the rotating tool from the work piece.

5. Returning to the start position and offsetting work piece for the next pass.

6. Removing any protruding flash material from the upcoming pass region using a scraping tool.

7. Repeating the steps above until one side of fuel plate was friction bonded.

8. Sanding and/or scraping protruding flash material from the work piece.

9. Flipping the clad/fuel pack over and resecuring it to the anvil.

10. Repeating the FB process on the second side.

Table 5. Friction bonding parameters used for the AFIP-4 fuel plate.

\begin{tabular}{|l|l|}
\hline \multicolumn{1}{|c|}{ Friction Bonding Process Parameter (FB-127) } & \multicolumn{1}{c|}{ Units } \\
\hline Down force range & $6500-6800 \mathrm{lb}$ \\
\hline Tool speed & $400-406 \mathrm{rpm}$ \\
\hline Feed rate (inches per second) & $40-44 \mathrm{ipm}$ \\
\hline Step over distance between passes & $0.5 \mathrm{in}$. \\
\hline Number of passes per side & $\begin{array}{l}\text { First side: } 6 \\
\text { Second side: } 8\end{array}$ \\
\hline
\end{tabular}

After the FB process was completed and before the "fuel plate" was removed from the anvil, plates were rough sanded, second side only, with 80 and 160 grit sandpaper to remove any flashing material - a source of scatter/noise when conducting ultrasonic testing (UT) characterization. Plates were also inscribed or stamped with an identification (ID). After removal of the work piece from the anvil, the nonbonded cladding material used for clamping the work piece to the anvil was sheared away.

Prior to final plate processing steps, friction-bonded fuel plates were characterized "qualitatively" for bonding and cladding thickness over the fuel zone region "min clad" using a UT work station. Details of UT characterization are discussed below in the Quality Assurance (QA) section.

\section{HIP PROCESSING FUEL PLATE FABRICATION}

The HIP process involves preparation of a HIP can assembly containing four AFIP-4 size HIP plate samples. Samples consisted of a prepared LEU10Mo fuel foil and a set of prepared 6061 aluminum cladding sheets/plates, with the "Pocket plate" having a pocket depth of $0.015 \mathrm{in}$. in the $0.040 \mathrm{in}$. this stock material. 
Each sample was separated in the HIP can assembly by a 0.005 -in.-thick grafoil interleaf and a 0.25 in. hardened steel "strong back," which facilitated a uniaxial bonding force during processing.

The preparation of the HIP can involve:

1. Cleaning/wiping down all HIP can components with ethanol and lint-free wipes

2. Stacking samples within a four-sided pre-welded HIP can

3. Clamping the remaining two sides of the HIP can into the final configuration

4. Edge welding of the configure HIP can in an argon glove box

5. He leak checking the assembled HIP can

6. Vacuum degassing the HIP can at $315^{\circ} \mathrm{C}$ for 4 hours

7. Crimp sealing the evacuation tube of the HIP can using resistance heating provided by a welding power supply and a hydraulic crimper

8. Loading the HIP can in the Eagle 8 HIP.

HIP processing was accomplished via heating to $560^{\circ} \mathrm{C}$ and establishing a 90 -minute hold temperature at 15 kilopound per square inch (ksi). The processed HIP can samples were retrieved by cutting away the sides the HIP can using a horizontal band saw. As each sample was removed, it was marked with a permanent marker relative to sample ID and orientation. The ID number was subsequently stamped in a region of the plate not being associated with the final fuel plate geometry. Samples were then subject to an initial plate surface sanding to remove the surface texture imparted by the presence of the grafoil sheets. Subsequently, UT characterization was performed to establish minclad measurements and presence of any debond indications in the processed samples.

\section{FINAL PROCESSING SEQUENCE}

Prior to final processing steps, UT characterization results and "location" radiographs were use to ascertain if any fuel foil material was disturbed during the FB process. Namely, whether the FB tool clipped the fuel foil and subsequently created and relocated fuel foil fragments. Also, to establish if sufficient cladding thickness was available to perform final finishing steps.

Based on a map of the plate thickness, established using micrometer measurements and the thickness of cladding above the fuel foil (as established with UT characterization), the fuel plate was sanded on both side to established a fuel plate having the desired overall thickness $(0.050 \pm 0.003)$ and a minimum cladding thickness of 0.006 in. over the fuel foil.

Once sanding of a fuel plate was complete, the location of the fuel zone relative to the course sheared fuel plate perimeter was determined using of a location radiograph. Next, with the aid of fuel plate drawing transparency/template, the final plate/foil position was marked, and the fuel plate sheared to near final size, which left $\sim 0.063$ in. additional material around the perimeter. Sheared material was collected for subsequent bend testing, with the location of each piece recorded and the edge nearest the fuel plate marked.

Next, the fuel plate was machined to the final size using a milling machine configured with an end mill tool operating at $1200 \mathrm{rpm}$ and 7 ips. A plate identification engraving was also applied $-\sim 0.005$-in. deep. 


\section{OXIDE COATING APPLICATION}

An oxide film "beohmite" was applied to the fuel plate using an autoclave treatment. Prior to autoclaving, fuel plates were chemically cleaned using the sodium hydroxide solution etching process described above, which included the nitric acid pickle and water-rinse steps. Approximately 0.0005-0.001 in. of cladding thickness was emoved during cleaning.

Two fuel plates were fully immersed in deionized water within the autoclave, with only their edges in contact with the plate holder. The oxide film was then applied using a 4-hour hold at $185^{\circ} \mathrm{C}$ and pressure of $\sim 160$ psi. Figure 9 below shows the autoclave time-temperature-pressure conditions. Following the oxide film treatment, immersion density measurements were obtained to obtain fuel plate volume. Subsequently, final dimensional inspection, final UT characterization, and a cleanliness inspection were performed.

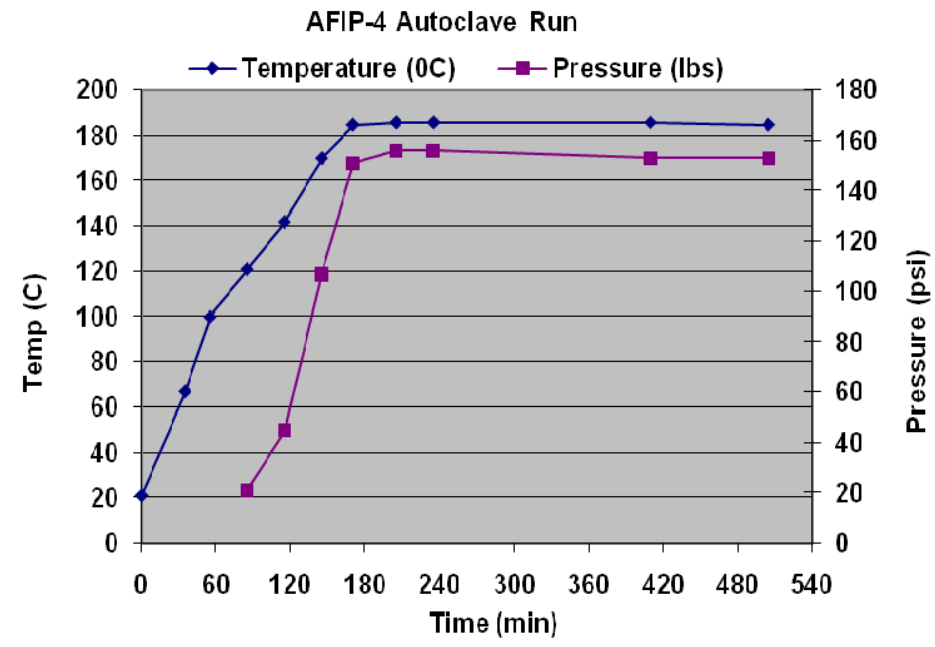

Figure 9. Autoclave schedule for AFIP-4 Fuel plates.

\section{FUEL PLATE ASSEMBLY}

Two fuel plate frame assemblies were qualified for the AFIP-4 experiment, A and B, per INL Drawing 759268, "AFIP-4 Fuel Plate Assembly." Figure 10 shows a representation of the loaded AFIP-4 fuel plate frame assemblies. Note that the top three and bottom three plates of each assembly were tack welded together prior to assembly loading; creating two fuel sample segments. Fuel sample segment were anchored in the frame assembly rails via two-tack welds at the midpoint of the frame assembly to accommodate thermal expansion. 


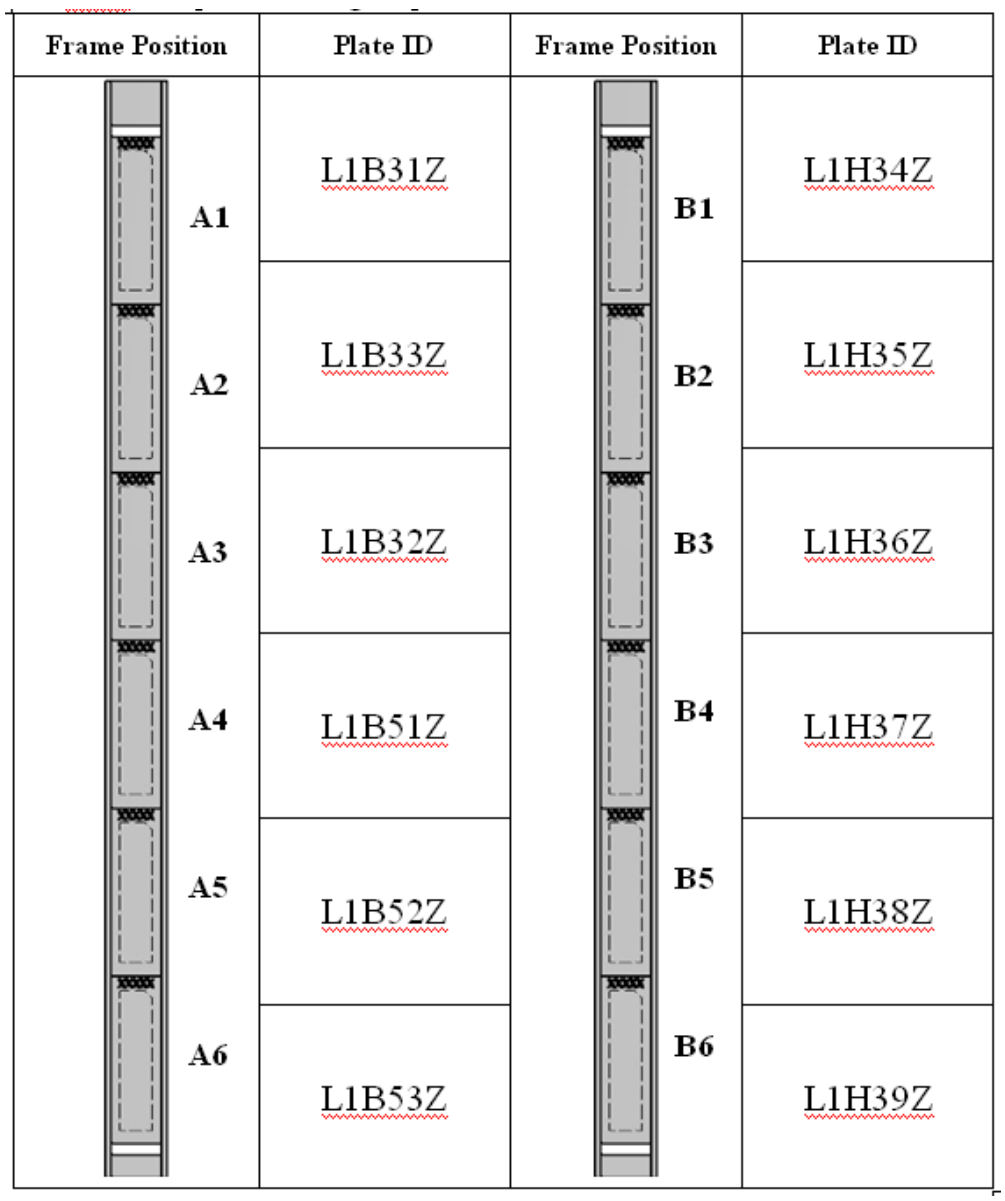

Figure 10. AFIP-4 fuel plate frame assembly construction: FB plates residing in A frame assembly and HIP plates in the B frame assembly.

\section{FUEL PLATE QUALITY ASSURANCE}

Candidate fuel plates designates as viable for insertion were subject to final inspection.

\subsection{Fuel Loading}

This section summarizes fuel loading calculations performed for AFIP-4 fuel plates. Fuel Loading Calculations for AFIP-4 Irradiation Experiment are detailed in ECAR-611, "Fuel Loading Calculations for the AFIP-4 Irradiation Experiment."

Candidate fuel plates were submitted to the MFC QA services for radiography. Radiographs were taken in the presences of a U10Mo tab-based reference standard, and densitometric measurements were acquired by qualified MFC QC personnel per TFR-491, "Fuel Plate Specification for the AFIP-4 Fuel Irradiation in the ATR." The densitometric data obtained were used to perform fuel loading calculations and establish if the fuel plates met the fuel loading acceptance criteria established. Namely, the Maximum Sllowable Calculated Thickness at any data point was 0.022 in. The Maximum Allowable Average Calculated Thickness for the overall plate was 0.016 in. (Table 6). 
Table 6. Summary of fuel loading acceptance criteria and AFIP-4 plate data.

\begin{tabular}{|c|c|c|c|}
\hline \multicolumn{2}{|l|}{ Fuel Loading Criteria } & & \\
\hline \multicolumn{2}{|c|}{ Maximum Allowable Calculated Thickness (each data point) } & & $0.018 \mathrm{in}$. \\
\hline \multicolumn{2}{|c|}{ Maximum Allowable Average Calculated Thickness (each plate) } & 0.018 in. & \\
\hline Plate Description & Plate & $\begin{array}{l}\text { Ave. Thick. } \\
\text { (in.) }\end{array}$ & $\begin{array}{c}\text { Maximum } \\
\text { Thickness } \\
\text { (in.) }\end{array}$ \\
\hline \multirow[b]{2}{*}{ U-10 Mo (Enrichment 19.92\%) Zr Co-Rolled, FB } & L1B31Z & 0.0127 & 0.0133 \\
\hline & L1B32Z & 0.0126 & 0.0135 \\
\hline \multirow[b]{4}{*}{ U-10 Mo (Enrichment 19.91\%) Zr Co-Rolled, FB } & L1B33Z & 0.0139 & 0.0145 \\
\hline & L1B51Z & 0.0128 & 0.0133 \\
\hline & L1B52Z & 0.0127 & 0.0135 \\
\hline & L1B53Z & 0.0130 & 0.0135 \\
\hline \multirow[b]{3}{*}{ U-10 Mo (Enrichment 19.92\%) Zr Co-Rolled, HIP } & L1H34Z & 0.0131 & 0.0138 \\
\hline & L1H35Z & 0.0131 & 0.0138 \\
\hline & L1H36Z & 0.0128 & 0.0134 \\
\hline \multirow[b]{2}{*}{ U-10 Mo (Enrichment 19.91\%) Zr Co-Rolled, HIP } & L1H37Z & 0.0126 & 0.0132 \\
\hline & L1H38Z & 0.0135 & 0.0142 \\
\hline
\end{tabular}

All candidate fuel plates were determined to have no fuel loading regions above the Maximum Allowable Calculated Thickness (for each data point acquired) and an average fuel loading below the Maximum Allowable Average Thickness, as reported in reported in ECAR-611.

The following section discusses the densitometric data collection process and the fuel loading calculation performed.

\subsection{Ultrasonic Testing (UT) Characterization}

This section summarizes the results of the ultrasonic inspection/evaluation of AFIP-4 fuel plates. A more detailed description of the UT characterization results can be found in TEV-503, "AFIP-4 A-B Fuel Plates Ultrasonic Debond, and Minclad Thickness Test Results."

The UT workstation with MFC-787 at the INL MFC consists of a water tank, sample holder, UT scanning hardware, and a data acquisition system (Figure 11). The data acquisition system used was a standards-based inspection/evaluation system. Two types of scans are acquired: Debond Scan that yields a single image/maps of ultrasonic signal transmission through a sample, and Minclad Scan that yields a series of images, via time-of-fight analysis/process of back reflections, representative of "reflection features" at a given depth from each face (near and far) of a sample. Reflection features arise from interfaces, inclusion, and/or voids. Both types of scans can be acquired simultaneously. 


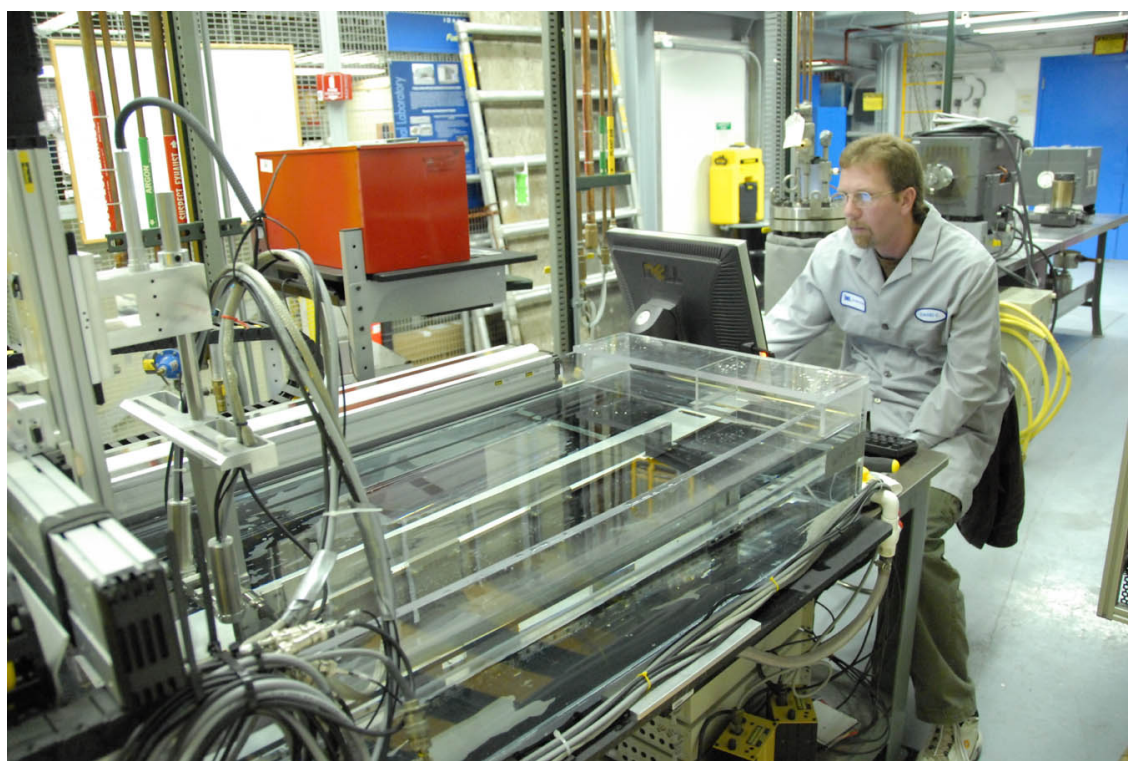

Figure 11. UT characterization workstation at INL MFC-787.

The Debond image/data was considered "for information only," but was acquired using a calibrated system. Calibrated reference standards were used to validate the system both before and after the inspection/evaluation. The Minclad inspection data was used for acceptance of meeting the fuel specification requirement for minimum cladding. Specifically, the cladding thickness above the fuel zone region of each fuel plate shall be determined using UT characterization. Each fuel plate shall be subjected to a minimum cladding UT scan. Traceable references standards are used to verify the minclad system calibration before and after the fuel plate was characterized. The minclad standard was an aluminum plate having engineered voids with known depths and diameters. Specifications for minimum cladding requirements are stated in Drawing 759269, “ATR Complex TRA-670 AFIP-4 Fuel Frame Plate Detail and Section," the minimum cladding thickness callout was 0.006 in.

When describing information obtained from UT characterization/analysis, near side and far side references were made relative to plate orientation in the UT tank; it was administratively established that a fuel plate sample was mounted for characterization with the ID stamp on the front (loading side) and right side of the established sample holder (thus the "front side of the plate" having the plate ID engraving was designated as the near side and the non-engraved side of the fuel plate was references and the "far side").

All candidate plates submitted for final UT characterization were found to be "acceptable", per the established Fuel Specification requirements.

\subsection{Fuel Out of Zone Inspection}

- Fuel out of Zone (FOZ) inspection was employed for the purpose of insuring that any stray particles outside of the maximum fuel region and plate edges and ends, as defined in INL Drawing 759269, do not violate the established acceptance criteria for use in the ATR. Specifically, stray fuel particles are allowed provided they do not violate the following:

One or more stray fuel particles, which fit in a square $0.5 \mathrm{~mm} \times 0.5 \mathrm{~mm}$ was acceptable and

- The stray fuel particle(s), which fit in the $0.5 \mathrm{~mm} \times 0.5 \mathrm{~mm}$ square, was/are no closer than $2 \mathrm{~mm}$ to any other $0.5 \mathrm{~mm} \times 0.5 \mathrm{~mm}$ square of particles edge to edge. and

- No stray fuel particle was closer to the plate edge or end than the major dimension of the particle. 
The FOZ inspection was conducted by a qualified inspector using a $5 \mathrm{x}$ magnifier, a transparency template of the fuel plate perimeter and maximum fuel zone, and radiograph(s) of the fuel plate acquired using conditions that yield high contrast of the fuel material and showing the plate's perimeter.

All 12 AFIP-4 samples met the FOZ acceptance requirements.

\subsection{Dimensional, Surface, and Cleanliness Inspection}

The dimensional and surface inspection was conducted by a qualified Inspector and per the fuel plate drawing, INL Drawing 759269, establishes that a candidate fuel plates meets (or not) the dimensional specifications established for length, width, and thickness. The minimum and maximum values of each dimension are recorded, as well as thirty thickness measurement values; for future use in establishing irradiated plate swelling. This data is recorded on the Fuel Plate Summary Sheet for each fuel plate, see Rec/Doc Id: AFIP-4, "Irradiation Experiment in the Advanced Test Reactor As-Built Data Package."

The criteria established for the visual cleanliness inspection are:

"Surface defects: such as scratches, marks, grooves, pores and other surface flaws greater than $0.203 \mathrm{~mm}$ (0.008in) deep, inside the maximum fuel zone shall be cause for rejection (using a template)".

All 12 AFIP-4 samples met the met the established dimensional, surface, and cleanliness inspection requirements.

\subsection{Bend Testing and Bend Test Sample Inspection}

Bend testing was utilized to insure that the FB process produces a complete aluminum-aluminum bond of the cladding material around the perimeter of the fuel zone region.

The bend test consists of the following steps:

1. Acquire samples from all sides of each plate. At least 12 bend samples adjacent to each plate (including five along each long side and one along each short side).

2. Mark the samples such that the edge nearest the fuel plate was established.

3. Clamp each sample in a test fixture and bending the sample around a $\sim 0.125 \mathrm{in}$. radius/mandrel 90 degrees from the starting position, return the sample to the initial position, bend the sample 90 degrees in the other direction, and bend the sample back to the original position.

4. Have the bend test samples visually inspected by a qualified inspector for any visual delamination of the edge indicated as adjacent to the fuel plate.

All AFIP-4 bend test samples/fuel plates met the acceptance criteria of the bend test inspection performed. 


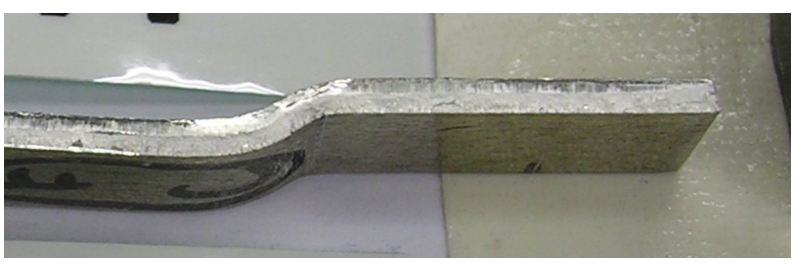

No Delamination

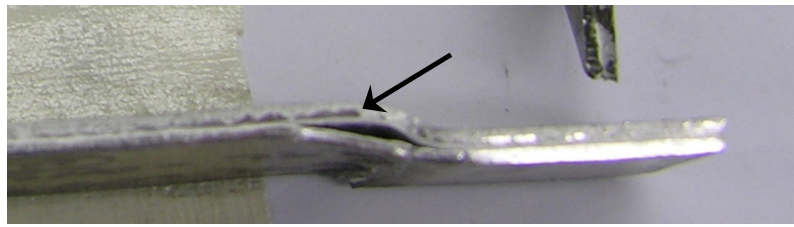

Delamination

Figure 12. Example of bend testing sample delamination.

\subsection{Radiological Release}

Prior to loading fuel plates in the test frame assembly, radiological smears were taken from both fuel plates. Smears were counter for signs of radiological surface contamination. All AFIP-4 fuel plates showed no detectable radiological contamination and were "free released" and assembled in the AFIP-4 fuel plate assemblies.

\subsection{Quality Assurance Data Review}

Qualification of fuel plate samples is accomplished by the preparation of an As-Built Data Package, AFIP-4. The As-Built Data Package contains documentation for each fuel specification required data/quality element (Table 7). After review by the project quality engineer, a "Green Tag" is issued for each qualifying sample. Green tags accompany the samples from the fabrication facility to the ATR.

Table 7. As-Built Data Package content list.

\begin{tabular}{|l|}
\hline \multicolumn{1}{|c|}{ As-Built Data Package Content List } \\
\hline QA Checklist \\
\hline Materials Certifications \\
\hline Plate Summary Sheet \\
\hline Uranium Cleaning Activity Sheet \\
\hline Alloy Tracking Spreadsheet \\
\hline Foil Cleaning and Final Dimensions Activity Sheet \\
\hline Friction Bonding or HIP Run Data Sheet \\
\hline Immersion Density Activity Sheet \\
\hline Dimensional and Surface Inspection Report \\
\hline Bend Tests Sample Inspection Report \\
\hline Fuel out of Zone (FOZ) Inspection Report \\
\hline Dimensional Inspection Report \\
\hline Autoclave Run Record \\
\hline Ultrasonic Characterization (UT) document reference \\
\hline Fuel Loading document reference \\
\hline Radiological Survey \\
\hline Assembly Loading Documentation \\
\hline Assembly Welding Documentation \\
\hline Non-Conformance Reports (NCRs) \\
\hline
\end{tabular}




\section{REFERENCES}

\section{Company-Controlled Documents and Drawings}

ECAR-611, "Fuel Loading Calculations for the AFIP-4 Irradiation Experiment," Rev. 0, April 29, 2009.

INL Drawing 759268, “ATR Complex TRA-670 AFIP-4 Fuel Frame Assembly and Details,” April 7, 2009.

INL Drawing 759269, “ATR Complex TRA-670 AFIP-4 FUEL Frame Plate Detail and Section,” April 7, 2009.

PLN-3028, "Experiment Control Plan for the AFIP-4 Fuel Irradiation in the ATR," Rev. 0, February 10, 2009.

PLN-3037, "Fabrication Control Plan for the AFIP-4 Experiment," Rev. 1, April 08, 2009.

Rec/Doc Id: AFIP-4, "Irradiation Experiment in the Advanced Test Reactor As-Built Data Package"

TEV-503, “AFIP-4 A-B Fuel Plates Ultrasonic Debond, and Minclad Thickness Test Results,” Rev. 0, April 29, 2009.

TFR-573, "Fuel Plate Specification For RERTR And AFIP Series Fuel Irradiations In The ATR," Rev. 3, January 12, 2010. 